\title{
Estudos psicométricos da Escala de Avaliação da Percepção da Religiosidade
}

\author{
Ana Paula Porto Noronha1, Paulo André Céo Rosa, Luiz Felipe Ayres Bernardes \\ Universidade São Francisco, Campinas-SP, Brasil
}

\section{RESUMO}

O objetivo do presente estudo foi investigar a estrutura interna da Escala de Avaliação da Percepção da Religiosidade (EAPRE), buscar evidências de sua validade com base na relação entre variáveis, por meio da comparação do nível de religiosidade dos participantes, e estimar a precisão do instrumento. Análises com o intuito de investigar diferenças de médias entre as variáveis idade e sexo também foram conduzidas; para tanto, dois estudos foram realizados. Da construção de itens participaram 39 pessoas e do instrumento aplicado foram gerados os 91 itens. O segundo estudo contou com 477 participantes que responderam a EAPRE. Dois fatores foram encontrados e os resultados foram favoráveis à validade e à precisão. As diferenças de médias indicaram que houve achados significativos para a externalização da religiosidade de acordo com a faixa etária, de modo que os mais velhos apresentam maiores médias. Não foram encontradas diferenças quanto aos sexos. Os resultados são discutidos à luz da literatura.

Palavras-chave: espiritualidade; psicologia positiva; avaliação psicológica.

\section{ABSTRACT - Studies on the psychometric properties of the Scale for the Assessment of Perceived Religiosity}

The purpose of this work was to investigate its internal structure, the validity evidences based on the relationship among variables by comparing the level of religiosity of the participants and estimating accuracy of the Escala de Avaliação da Percepção da Religiosidade. Studies in order to examine mean differences between age and gender were also conducted. To this end, two studies were conducted. 39 participants took part in building items and, from the instrument applied, 91 items were generated. The second study included 477 participants who answered Perception Scale of Religiosity. Two factors were found and the results were favorable to the validity and reability. Differences in means indicated that there were significant findings for the externalization of religiosity. Therefore, older participants had higher averages. No differences regarding gender were found. The results are discussed based on the literature available.

Keywords: spirituality; positive psychology; psychological evaluation.

\section{RESUMEN - Estudios psicométricas de la Escala de Evaluación de la Percepción de la Religiosidad}

El objetivo del estudio fue investigar la estructura interna, la validez basada en la relación entre variables por medio de la comparación del nivel de religiosidad de los participantes, y estimar la confiabilidad de la Escala de Avaliação da Percepção da Religiosidade. También se llevaron a cabo estudios con la finalidad de examinar las diferencias de medias entre la edad y el sexo. Para eso fueron realizados dos estudios. De la construcción de ítems participaron 39 personas y del instrumento aplicado fueron generados 91 ítems. El segundo estudio contó con 477 participantes que respondieron a la Escala de Percepción de la Religiosidad. Dos factores fueron encontrados y los resultados fueron favorables a la validez y confiabilidad. Las diferencias de medias indicaron que hubo hallazgos significativos para la externalización de la religiosidad, de tal modo que los participantes de mayor edad presentaron mayores medias. En relación a los sexos no se encontraron diferencias. Los resultados son discutidos con base en la literatura.

Palabras clave: espiritualidad; psicología positiva; evaluación psicológica.

A religiosidade, embora não seja uma temática nova, possibilita, ainda na Contemporaneidade, uma ampla discussão; a esse respeito, Lo Bianco e Vidal (2014) evidenciam que os movimentos religiosos indicam a busca da felicidade ou o alívio do sofrimento, o que justifica sua permanência ao longo da História. Lotufo Neto (1997) contextualiza que a religião é uma das "instituições" mais antigas, o que não permite sua dissociação da história da cultura humana. De acordo com Emmons e Paloutzian (2003), a discussão da religião voltada à Psicologia se tornou mais evidente após a criação da American Psychological Association Division 36, em 1976. À época, a produção era muito incipiente, sendo que a elaboração de livros se deu mais fortemente durante os anos 1980 e os periódicos se estabilizaram ao longo da década de 1990. 
Segundo Pargament (2002), muitos pensadores teorizaram sobre os benefícios e malefícios da religiosidade, como, por exemplo, James Leuba, que a categorizou como irracional e patológica; e Sigmund Freud, que a definiu como perigosamente ilusória. Adicionalmente, o pesquisador destaca William James, que compreendia a religiosidade como um caminho para a maior das potencialidades humanas; Carl Jung, que a definiu como fonte de equilíbrio, harmonia e plenitude; ou Erik Erikson, que atribuiu a ela um caráter processual, com vistas à busca de sabedoria e maturidade.

Em uma análise mais recente, Ávila (2007) afirma que, ao mesmo tempo em que tem ocorrido com mais frequência, tem sido um desafio a busca pela reflexão sobre o tema. Em alguma medida, isso também é compartilhado por Fleck (2000), Emmons e Paloutzian (2003), Schultz, Tallman e Altmaier (2010), Schuurmans-Stekhoven (2013) e Vaillant (2013), ao defenderem que nas últimas décadas os aspectos "não materiais", ou espirituais, têm sido mais valorizados, de modo que se pode constatar na Psicologia um renovado interesse pelo assunto. Oliveira e Balbinotto Neto (2014) apresentam dados referentes à participação religiosa no mundo e afirmam que aproximadamente $90 \%$ da população mundial possui algum tipo de crença.

De acordo com Miller e Thoresen (2003), em grande parte da literatura das Ciências Sociais os termos espiritualidade e religiosidade têm sido tratados como sinônimos. No entanto, para os autores há diferenças entre eles; espiritualidade seria o mais amplo e envolveria os aspectos não materiais da vida; religiosidade e religião estariam relacionados a "entidades sociais", com crenças, práticas e normas (Roehe, 2004). Nessa mesma direção, Emmons e Paloutzian (2003) atribuem à espiritualidade a existência de forças não materiais e, mais especialmente, o conceito de que ela é um fenômeno humano universal.

Mattis (2000) e Zinnbauer et al. (1997) já haviam afirmado que a espiritualidade é universal, embora o conteúdo específico de crenças espirituais varie em cada cultura. Além disso, as religiões procuram ajudar as pessoas a lidar com o núcleo existencial das preocupações, com as regras e os valores que norteiam as relações dos indivíduos, bem como os seus esforços para lidar com as dificuldades da vida. Os mesmos autores sugeriram que religiosidade e espiritualidade traduzem a crença na existência de uma dimensão transcendente da vida. A diferenciação entre eles refere-se ao fato de a religiosidade descrever um grau de aceitação das crenças do indivíduo associado à adoração de uma figura divina e defender a participação do indivíduo em atos de culto. Espiritualidade, de modo distinto, é a crença para descrever uma relação íntima entre os seres humanos e o divino, bem como as virtudes que advêm da interação.

O presente trabalho teve o objetivo de versar sobre a percepção da religiosidade, embora não tenha se voltado a uma religião específica, mas a qualquer forma de expressão, ainda que não praticada por meio das religiões formais. Para Paiva et al. (2004), a experiência religiosa é um processo psicológico complexo, que envolve os sentidos, a cognição e o afeto. Dessa forma, poderia ser compreendida como um conceito multifacetado, pois há variadas formas de se perceber como religioso ou de comportar-se como tal. Adicionalmente, indivíduos podem externar religiosidade em alguns aspectos, mas não em outros. A ideia de Ávila (2007) define religiosidade como comportamentos, atitudes e crenças que tenham conteúdo religioso.

Shannon (2004), por sua vez, reconhece que a religiosidade possui dois componentes inerentes, quais sejam: o extrínseco e o intrínseco. O primeiro está mais voltado à demonstração do comportamento religioso e, em razão disso, é considerado externo. A título de exemplo, citam-se a ida ao templo religioso e a participação nos grupos de discussão. A seu turno, o segundo (intrínseco) diz respeito ao valor que o indivíduo atribui à religião e, por essa razão, é considerado como um processo interno. Perdoar, ser compreendido e generoso, por exemplo, podem ser citados para ilustrar. Lotufo Neto (1997), ao abordar o conceito de extrínseco e intrínseco, faz menção à Allport e Ross (1967), que definiram o primeiro como um "meio" para atingir um "fim", enquanto religiosidade intrínseca é compreendida como algo possível de atribuir um significado à vida do indivíduo.

Ainda quanto ao conceito de intrínseco e extrínseco, Kahoe (1977), em seus estudos realizados há mais de três décadas, examinou a relação entre religiosidade e sexo. $\mathrm{O}$ autor encontrou associação moderada negativa entre religiosidade intrínseca e atitudes que são favoráveis às diferenças entre sexos (apenas para as mulheres). Adicionalmente, ele encontrou uma associação positiva, embora não significativa, para o sexo masculino. $\mathrm{O}$ autor sugere que sejam realizados estudos para investigar outras variáveis, como frequência à igreja, participação comunitária, crenças, entre outras. Já sob a ótica de Tinoco-Amador (2009), a religiosidade é um construto que se refere a processos ideológicos, com o intuito de "significar" a vida do indivíduo. Para ele, as práticas, os costumes e os hábitos estão relacionados às percepções religiosas e é por meio delas que se mantém a crença em um mundo melhor (e, por vezes, diferente do atual). Assim, a percepção de religiosidade deveria ser entendida como um elemento estrutural da socialização dos indivíduos, a ponto de poder regular suas relações sociais.

Diferentemente da concepção de dois fatores, Glock (1962) organizou as dimensões básicas da religião em cinco: ritualista, vivencial, ideológica, intelectual e consequencial. A participação das pessoas em cultos/missas, as orações, o jejum ou outros momentos ritualísticos representa a primeira dimensão. $\mathrm{Na}$ vivencial, estaria implícita a vivência subjetiva da fé, ou seja, relaciona-se à vivência "emocional", sem necessidade de exteriorização. De acordo com o autor, o ideológico é o que leva 
a pessoa a ter algumas crenças ou preceitos, como, por exemplo, a ideia de que Deus a escuta. A dimensão intelectual relaciona-se ao conhecimento das doutrinas e dos textos sagrados. A quinta e última dimensão é a consequencial, ou seja, as boas obras ou os efeitos das outras dimensões. Ruppel (1969) complementa a concepção de Glock. Para ele, a experiencial se refere aos sentimentos e às emoções; a ritualística, ao comportamento religioso; a ideológica, às crenças; a intelectual, ao conhecimento; e a consequencial, aos efeitos das palavras seculares e outras dimensões da religiosidade.

Peterson e Seligman (2004), sob a perspectiva da Psicologia Positiva, fizeram uma síntese de aspectos da espiritualidade/religiosidade que precisam ser mais investigados empiricamente. Em relação ao sexo, por exemplo, embora os estudos sugiram diferenças nos padrões de religiosos, faltam informações sobre desenvolvimento e principais influências. Nessa mesma direção, faltam pesquisas longitudinais e sobram dúvidas quanto às relações entre padrões e idades. Ademais, é necessário dar maior atenção para o processo (se inter e intrageneracional) pelo qual os valores e as crenças religiosas e espirituais são transmitidos. Por fim, os autores sugerem que as associações entre espiritualidade e outros construtos, como culpa, perdão, sabedoria, esperança, compaixão e amor, sejam demonstradas.

A esse respeito, convém destacar as asserções de Tinoco-Amador (2009), no sentido de que o construto é um elemento estrutural na organização da vida social e individual. Sob essa perspectiva, é imprescindível que sua medição se dê com base em instrumentos que possuam suas qualidades psicométricas garantidas (Urbina, 2007) e, nesse particular, que considere variáveis distintas na realização das pesquisas. Estas, por sua vez, devem também utilizar instrumentos que tenham estudos de validade e precisão ou mesmo devem propiciar tais características. Isso permitirá que inferências sejam feitas a fim de localizar um indivíduo em um grupo e que, ao investigar grupos, se tenha clareza das semelhanças e diferenças entre indivíduos (Tinoco-Amador, 2009).

Entre os estudos empíricos que se destinaram a pesquisar algum fenômeno relacionado à temática do presente artigo, destaca-se o realizado por Ocampo, Romero, Saa, Herrera e Reyes-Ortiz (2006), que, com o intuito de determinar a prevalência das práticas religiosas, suporte social e disfunção familiar, aplicaram uma Escala de Avaliação da Religiosidade Extrínseca-Intrínseca, uma Prova de Avaliação da Dinâmica Familiar e uma Escala de Depressão Geriátrica. Em relação às questões voltadas à religiosidade, os achados revelaram que 93\% da amostra orava ao menos uma vez por dia; a orientação religiosa extrínseca estava presente em $33,8 \%$, ao passo que a intrínseca, em $54,4 \%$ (os demais tinham orientação mista); e 53,6\% frequentavam o templo uma ou duas vezes por semana.
As associações entre experiências de culto formal e medidas de religiosidade foram estudadas por Gunnoe e Beversluis (2009). As experiências de culto incluíram "Pertença" e "Construção de significados" (tradicionalmente vistos como os dois melhores preditores da religiosidade) e duas experiências mais recentemente identificadas como aspectos críticos de Socialização em comunidades religiosas: "Abertura à autoridade de Deus" e "Liderança juvenil nos cultos". As medidas de religiosidade da juventude, por sua vez, envolveram aspectos como a avaliação dos jovens de seu relacionamento com Deus, sua identidade religiosa, além da frequência da oração pessoal. Nas análises de regressão múltipla, a relação dos jovens com Deus foi melhor predita pela "Abertura à autoridade de Deus". Ao lado disso, a identidade e o comportamento religiosos foram consistentemente previstos pela "Liderança juvenil nos cultos".

O estudo de Kim-Spoon, Longo e McCullough (2012) buscou compreender se a dinâmica da relação pais/adolescentes influencia na transmissão intergeracional de religiosidade para os adolescentes e na capacidade de ajustamento dos adolescentes frente à relação com seus pais e à religiosidade deles. Após avaliação, modelos equacionais estruturais sugeriram relação significativa indireta entre religiosidade de pais e filhos. Em acréscimo, foi encontrada relação negativa entre a religiosidade dos pais e os sintomas de religiosidade intrínseca dos adolescentes.

Tinoco-Amador (2009) objetivou analisar as atitudes de jovens sobre a religiosidade. Para tanto, ele utilizou um instrumento que continha 64 itens relacionados aos hábitos, às percepções e aos valores religiosos. Mais especialmente, os itens abordavam "Igreja e liturgia", "crença em Deus", "ritos e Igreja" e "sacramentos", entre outros. Os resultados indicaram diferenças significativas entre sexos, embora em número diminuto de aspectos, tal como destacado pelo autor, sendo alguns favoráveis às mulheres, e outros, aos homens. A título de conclusão, ele afirma que a religiosidade é um construto permeado por processos ideológicos que dão sentido à vida dos indivíduos.

A relação entre a religiosidade e o bem-estar conjugal foi objeto de interesse de Day e Acock (2013). Os dados para análise foram retirados de um estudo longitudinal de três anos. Os resultados indicaram que relacionamentos permeados por religiosidade possuem associação positiva (mediada pelas virtudes relacionais) com bem-estar conjugal, mas não encontrou relação com situação de desigualdade entre os casais. O autor faz uma ressalva, no sentido de que a religiosidade não está diretamente relacionada a relacionamentos sólidos, mas está relacionada às virtudes, que, por sua vez, estão associadas ao bem-estar conjugal.

Ainda, com vistas a analisar se a espiritualidade/religiosidade, sob a perspectiva da Psicologia Positiva, é preditiva de bem-estar subjetivo (BES), 
Schuurmans-Stekhoven (2013) aplicou três instrumentos: questionário sociodemográfico, instrumento de avaliação de BES e outro de forças e virtudes. Os achados indicaram que a espiritualidade/religiosidade prediz mais fortemente as demais forças do que o BES. A realização deste estudo foi proposta com o objetivo de buscar evidências de validade com base na relação entre variáveis, por meio da comparação do nível de religiosidade dos participantes, e estimar a precisão de uma escala de percepção da religiosidade. Como objetivo secundário tem-se a análise da estrutura interna e de eventuais diferenças de médias entre idades e sexo.

Utilizou-se como fundamento teórico a concepção de que o construto é constituído por uma dimensão interna e outra externa, em relação à qual Allport e Ross (1967), Lotufo Neto (1997) e Shannon (2004) teceram as considerações apresentadas. Para tanto, foram realizados dois estudos, cujas descrições serão apresentadas. Convém destacar que o primeiro objetivou construir o instrumento, enquanto o segundo contemplou os demais objetivos já citados.

\section{Método}

\section{Estudo 1}

Participantes. Participaram 39 pessoas com idades entre 19 e 75 anos $(M=46,74 ; D P=13,56)$, sendo $66,7 \%$ do sexo feminino e 33,3\% do masculino. Com relação ao nível educacional, $33,3 \%$ possuíam ensino médio completo, $30,8 \%$, o superior completo, $7,7 \%$, o superior incompleto, $5,1 \%$, o ensino fundamental incompleto, e $2,6 \%$, os ensinos fundamental completo e médio incompleto - destacase que $17,9 \%$ não responderam. Os participantes foram convidados pela rede de contatos dos autores.

Instrumento - Questionário de Percepção da Religiosidade. A construção de itens se deu a partir da elaboração de um questionário que contava com uma pergunta aberta, na qual os respondentes deveriam listar 15 características que traduzissem o "viver religiosidade". Além disso, havia uma seção para os dados de identificação.

Procedimentos. O presente estudo encontra-se inserido em um projeto mais amplo da primeira autora, cujo parecer do Comitê de Ética em Pesquisa da Universidade São Francisco é favorável. Isso posto, os participantes foram selecionados por conveniência; eles foram esclarecidos quanto ao objetivo do estudo e responderam coletivamente às questões em locais diversos, como sala de aula, sala de reuniões ou outros ambientes institucionais, após as respectivas aprovações dos dirigentes e a assinatura ao Termo de Consentimento Livre e Esclarecido (TCLE). Não havia tempo limite para a resposta, mas, em média, os participantes usaram 10 minutos.
Plano de análise de dados. A análise envolveu a reunião dos argumentos que tinham o mesmo sentido, o que foi realizado pelos dois primeiros autores conjuntamente. Em seguida, realizou-se a análise de frequência.

Resultados. A aplicação resultou em 535 unidades de respostas, que foram digitadas em planilha eletrônica para posterior análise. As respostas foram agrupadas pelos autores, com o intuito de reduzir as que tinham o mesmo sentido, mas encontravam-se construídas com algumas diferenças semânticas. A título de exemplo, pode-se citar "Amar os irmãos sem distinção" e "Tratar as pessoas como semelhantes" ou, ainda, "Participar da vida comunitária" e "Ser membro ativo em sua comunidade". Assim, chegou-se consensualmente aos 91 itens que compuseram a Escala de Avaliação da Percepção da Religiosidade (EAPRE). Do total, 21 ideias não puderam ser aproveitadas em razão da falta de relação com a proposta, o que representou $4 \%$ do total.

\section{Estudo 2}

Participantes. Fizeram parte do estudo 477 pessoas, com idades entre 17 e 70 anos, sendo a média 29,9 $(D P=12,250)$. Quanto ao sexo dos respondentes, 55,1\% eram mulheres e $44,9 \%$, homens; no entanto, convém destacar que 87 pessoas não preencheram esses dados de identificação. A maioria dos indivíduos tinha ensino superior incompleto $(64,4 \%)$, enquanto uma menor parte tinha ensino médio completo $(15,6 \%)$ e superior completo $(12,0 \%)$. Os demais se dividiram entre ensino fundamental completo $(2,3 \%)$ ou incompleto $(1,7 \%)$ e médio incompleto $(3,4 \%)$. Apenas quatro pessoas não indicaram o grau de instrução. Todos os participantes eram de uma cidade próxima a Campinas, Estado de São Paulo.

A religião também foi investigada nesse primeiro momento, sendo que foram encontrados nove títulos diferentes: católico, cristão, espírita, protestante, evangélico, budista, messiânico, presbiteriano e agnóstico. A maioria dos respondentes $(83,7 \%)$ afirmou ser católica, embora alguns participantes não tenham respondido $(n=102)$.

\section{Instrumento-Escala de Avaliação da Percepção} da Religiosidade. O instrumento possui duas seções, sendo a primeira responsável pelo levantamento dos dados de identificação dos participantes, tais como idade, sexo, religião e nível de religiosidade. Em especial, em relação ao último, o indivíduo deveria indicar o seu grau de envolvimento com a religião, em uma escala de 4 pontos, variando de nenhum a alto. A segunda seção se inicia com a instrução e um exemplo sobre a tarefa a ser desempenhada. Em seguida, são apresentados os 91 itens em escala Likert, variando de 1 (pouco) a 5 (muito).

Esses itens indicam ações relacionadas à prática religiosa, tais como "ler a Bíblia”, "educar as pessoas na Fé" e 
"rezar", de modo que quanto maior a pontuação do participante, mais ele se perceberá como religioso. A pontuação máxima é de 455, e a mínima, de 91.

Procedimento. Após a assinatura do TCLE, deu-se início à coleta de dados. Os participantes eram orientados quanto ao preenchimento do instrumento. $\mathrm{O}$ tempo de aplicação médio foi de 25 minutos. As aplicações ocorrem em locais distintos, tal como já informado.

Plano de análise de dados. Para definir o número de fatores a serem extraídos, foi utilizada inicialmente a análise paralela (Horn, 1965); em seguida, empregou-se o método de Hull (Lorenzo-Seva, Timmerman, \& Kiers, 2011). A análise dos componentes principais, o método multivariado mais usado para redução de dados (Damásio, 2012), e o alfa de Cronbach foram empregados.

\section{Resultados}

A primeira análise dos eigenvalues obtidos por meio da produção de matrizes randômicas para 91 variáveis e 477 participantes indicou qutro fatores, sendo aqueles cujos eigenvalues da matriz experimental foram superiores aos gerados por uma matriz de dados aleatórios (O'Connor, 2000) (Tabela 1).

O método de Hull também foi aplicado com o intuito de verificar o ajuste ao modelo testado. Investigou-se o índice de ajuste Comparative Fit Index (CFI), sendo que foram testados quatro fatores, tal como indicado pela análise paralela, e dois, com base nos pressupostos teóricos. Os resultados revelaram $\mathrm{CFI}=0,75$ para 4 fatores, e $\mathrm{CFI}=0,67$ para 2 , ambos inferiores a 0,90 , o que é considerado um ajuste adequado (Hu \& Bentler, 1999).

Dando sequência à análise da estrutura interna, os estudos incluíram a análise do Kaiser-Meyer-Olkin (KMO) e o teste de esfericidade de Bartlett's, a fim de obter informações sobre a possibilidade de fatoração da escala. O primeiro indicou um coeficiente de 0,945,

Tabela 1

Resultados referentes à análise paralela

\begin{tabular}{lccc}
\hline \multirow{2}{*}{ Fatores } & $\begin{array}{c}\text { Dados } \\
\text { experimentais }\end{array}$ & \multicolumn{2}{c}{ Dados aleatórios } \\
\cline { 2 - 4 } & Eigenvalue & $\begin{array}{c}\text { Eigenvalue } \\
\text { médio* }\end{array}$ & $\begin{array}{c}\text { Eigenvalue } \\
\text { P95** }\end{array}$ \\
\hline 1 & 31,7 & 4,4 & 4,7 \\
2 & 10,9 & 2,8 & 3,0 \\
3 & 3,4 & 2,7 & 2,8 \\
4 & 2,8 & 2,6 & 2,7 \\
5 & 2,5 & 2,5 & 2,6 \\
6 & 2,0 & 2,4 & 2,5 \\
\hline
\end{tabular}

Nota: * Média dos resultados de 1.000 matrizes geradas aleatoriamente;

**Valores de eigenvalues obtidos no percentil 95. enquanto o segundo, de 23.205,10 ( $p<0,001)$, permitindo inferir que a investigação dos componentes principais poderia ser realizada.

Foram identificados 19 componentes com autovalores superiores a 1,0, representando $63,0 \%$ da variância explicada sem rotação, por meio da análise dos componentes principais. O gráfico de sedimentação sugeriu as possibilidades de extração de um, dois, três ou quatro fatores. A solução de dois fatores foi a mais coerente sob a perspectiva teórica, tendo sido eleita para a continuidade das análises. Os dados foram estudados pela análise de eixos principais, rotação Promax, portanto oblíqua; para simplificar, a estrutura das cargas corresponde a uma rotação não rígida do sistema de coordenadas (Dancey \& Reidy, 2006) (Figura 1).

A correlação $r$ de Pearson entre os fatores 1 e 2 foi de $r=0,42(p<0,001)$, portanto moderada. Foi estabelecido que os índices de saturação deveriam ser superiores ou iguais a 0,40. Com isso, 17 dos 91 itens iniciais foram eliminados. A variância explicada para dois componentes foi de $39,0 \%$. Assim, o primeiro ficou composto por 32 itens, quais sejam, ler a Bíblia, ir à missa, participar da eucaristia, confessar, ser missionário, visitar doentes, ter vida de oração, viver a palavra, viver os sacramentos, educar na fé, viver em comunhão, fazer jejum, buscar santidade, ouvir músicas, evangelizar, assistir palestras, entre outros. A ele atribuiu-se o nome de Externalização da Religiosidade. Já o segundo reuniu 42 itens e recebeu o título de internalização da religiosidade, dentre os quais destacam-se: ser humilde, amar ao próximo, respeitar o ser humano, ser solidário, ser sereno, perdoar, ser justo, buscar a felicidade, compreender o outro, ser sincero, ser compreensivo e ser simples (Tabela 2).

Foram estudadas eventuais diferenças (na variância dos grupos) de médias em relação à idade, ao sexo, ao grau de escolaridade e à percepção de religiosidade. Para a idade, os participantes foram organizados em três grupos em razão dos quartis, sendo que o grupo 1 incluiu aqueles com idades até 21 anos; no grupo 2 ficaram os participantes com idades entre 21,1 e 35,9 anos; e, por fim, no grupo 3, estavam aqueles com 36 anos ou mais. Os resultados revelaram diferença significativa apenas para o fator Externalização da Religiosidade $[F(2 ; 477)=16,381 ; p<0,001]$. A fim de compreender como as idades se organizaram, realizou-se a prova post hoc de Tukey, cujos achados podem ser visualizados na Tabela 3 .

Foi possível constatar a organização de dois conjuntos, de modo que os indivíduos mais velhos tiveram médias maiores e ficaram separados das demais idades. A diferença entre os sexos também foi objeto de investigação. Os resultados não foram significativos, sendo que os homens e as mulheres da amostra não se distinguem quanto à externalização $(t=-0,940 ; p=0,348 ; d=0,096)$ e à internalização da religiosidade $(t=0,078(t=-0,498)$; $p=0,619 ; d=0,051)$. 
Ao investigar as médias referentes a grupos formados pelo grau de instrução encontrou-se diferença significativa. Por meio da ANOVA, obteve-se que no fator Externalização os indivíduos que assinalaram "Ensino superior incompleto" tiveram diferenças referente aos grupos de "Ensino médio completo" e "Ensino superior completo". Já diante do fator internalização, levantaram-se diferenças entre sujeitos de "Ensino médio completo" e "Ensino superior incompleto".

As diferenças de média quanto aos fatores da EAPRE e o nível de religiosidade foram analisadas com vistas à busca de evidências de validade com base na relação entre variáveis. No instrumento, o participante atribuiu um valor de $1 \mathrm{a} 4$ à sua percepção de religiosidade. Houve significância para ambos os fatores, a saber, externalização $[F(3,477)=103,350 ; p<0,001]$ e internalização $[F(3,477)=9,103 ; p<0,001]$.

As provas post hoc de Tukey, dispostas nas Tabelas $4 \mathrm{e}$ 5 , revelaram que quanto mais alto o sujeito percebe o seu nível de religiosidade, mais ele pontua na EAPRE, no que se refere à externalização, de modo que foram formados quatro conjuntos distintos. No entanto, em relação ao segundo fator da EAPRE (internalização), apenas dois conjuntos foram organizados, sendo que os participantes com menor percepção de religiosidade ficaram separados daqueles com maior percepção.
A fim de verificar a precisão do instrumento, foram obtidos os alfas para ambos os fatores. O primeiro teve um índice de 0,953 e o segundo, de 0,938, ambos bastante bons. Com o intuito de apresentar uma análise mais detalhada dos itens, foram calculadas as variações que os valores de alfa teriam, caso algum item fosse retirado. O cálculo foi feito para cada fator e seus resultados podem ser visto na Tabela 6 . Como é possível observar, nenhum item possibilita o aumento do coeficiente alfa. Assim, conclui-se que de uma forma geral os itens compõem um instrumento com um índice bastante bom de precisão, quando analisada pela consistência interna.

\section{Discussão}

A justificativa para a realização do presente estudo pode tomar emprestadas as asserções de Fleck (2000), ao afirmar que nos últimos anos os aspectos "não materiais" ou espirituais têm sido mais valorizados, assim como de Oliveira e Balbinotto Neto (2014), cujos dados apresentados refletiram a maciça participação religiosa no mundo. Também nessa direção, Lo Bianco e Vidal (2014) asseveram que é possível observar diferenças entre indivíduos que se associam e que não se associam à religião, sobretudo se for considerado o possível caráter apaziguador das violências e dos conflitos contemporâneos.

Scree plot

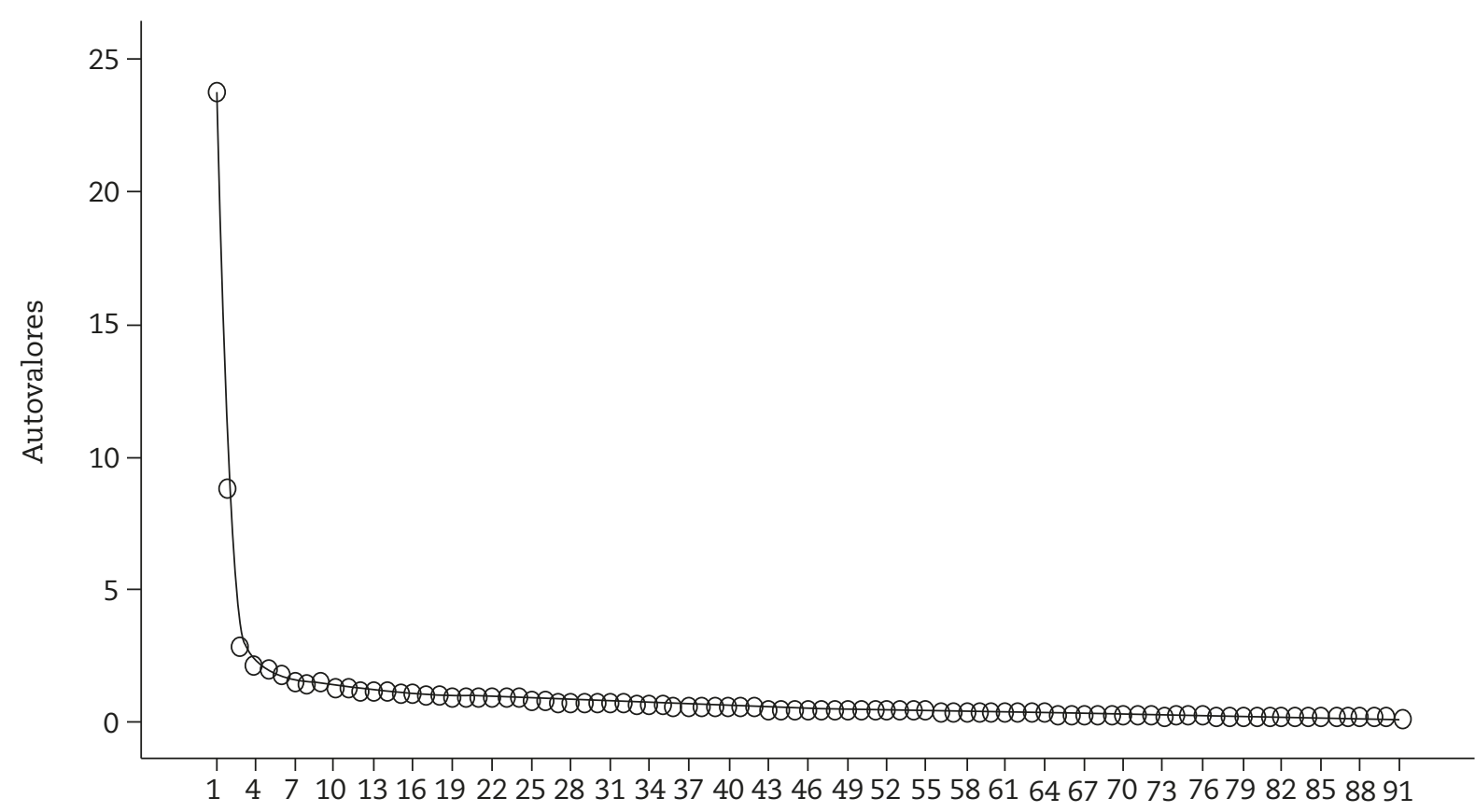

Número de componentes

Figura 1. Gráfico de sedimentação da Escala de Avaliação da Percepção da Religiosidade 
Tabela 2

Saturação (superior a 0,40) por componentes, com rotação Promax e normalização de Kaiser, eigenvalues e variância explicada

\begin{tabular}{|c|c|c|}
\hline \multirow{2}{*}{ Itens } & \multicolumn{2}{|c|}{ Componentes } \\
\hline & 1 & 2 \\
\hline 1. Ler a Bíblia & 0,802 & \\
\hline 2. Ir à missa & 0,823 & \\
\hline 7. Participar na eucaristia & 0,787 & \\
\hline 8. Confessar & 0,709 & \\
\hline 9. Ser humilde & & 0,593 \\
\hline 10. Amar o próximo & & 0,508 \\
\hline 11. Ser missionário & 0,720 & \\
\hline 12. Respeitar o ser humano & & 0,528 \\
\hline 13. Visitar doente & 0,484 & \\
\hline 14. Ter vida de oração & 0,691 & \\
\hline 16. Viver a palavra & 0,504 & \\
\hline 17. Ser prestativo & & 0,624 \\
\hline 18. Ser solidário & & 0,565 \\
\hline 20. Viver os sacramentos & 0,652 & \\
\hline 21. Educar na fé & 0,747 & \\
\hline 23. Viver em comunhão & 0,592 & \\
\hline 25. Perdoar & & 0,533 \\
\hline 26. Ser sereno & & 0,548 \\
\hline 28. Ser perseverante & & 0,472 \\
\hline 29. Fazer jejum & 0,599 & \\
\hline 30. Buscar santidade & 0,728 & \\
\hline 31. Ouvir músicas & 0,644 & \\
\hline 33. Fazer meditação & 0,404 & \\
\hline 35. Fazer o bem & & 0,692 \\
\hline 36. Ser acolhedor & & 0,590 \\
\hline 37. Buscar a felicidade & & 0,661 \\
\hline 38. Ser justo & & 0,698 \\
\hline 39. Ser sincero & & 0,655 \\
\hline 40. Compreender & & 0,584 \\
\hline 41. Tratar semelhantes & & 0,612 \\
\hline 42. Conviver em harmonia & & 0,606 \\
\hline 43. Fazer penitência & 0,561 & \\
\hline 45. Evangelizar & 0,859 & \\
\hline 46. Assistir a palestras & 0,793 & \\
\hline 47. Ler livros & 0,786 & \\
\hline 48. Escolher com amor & & 0,553 \\
\hline 50. Ser compreensivo & & 0,654 \\
\hline 52. Respeitar diferenças & & 0,461 \\
\hline 53. Ser fraterno & & 0,611 \\
\hline 54. Ser amável & & 0,740 \\
\hline 55. Estar a serviço & & 0,431 \\
\hline 57. Diálogo ecumênico & 0,466 & \\
\hline 58. Autoaceitação & & 0,484 \\
\hline 59. Procurar ser melhor & & 0,587 \\
\hline 60. Ser simples & & 0,620 \\
\hline 61. Fazer com amor & & 0,565 \\
\hline 62. Colocar-se no lugar & & 0,498 \\
\hline 63. Praticar os mandamentos & 0,567 & \\
\hline
\end{tabular}

Tabela 2 (continuação)

Saturação (superior a 0,40) por componentes, com rotação Promax e normalização de Kaiser, eigenvalues e variância explicada

\begin{tabular}{|c|c|c|}
\hline Itens & 1 & 2 \\
\hline 64. Estender a mão & & 0,556 \\
\hline 65. Conhecer a religião & 0,602 & \\
\hline 66. Ouvir a palavra & 0,683 & \\
\hline 67. Entregar dia & 0,674 & \\
\hline 68. Viver batismo & 0,757 & \\
\hline 69. Participar de movimentos & 0,789 & \\
\hline 70. Visitar os pobres & 0,538 & \\
\hline 71. Respeitar a família & & 0,462 \\
\hline 73. Respeitar os idosos & & 0,520 \\
\hline 74. Partilhar & & 0,528 \\
\hline 75. Rezar inimigos & 0,456 & \\
\hline 76. Ter posição justa & & 0,609 \\
\hline $\begin{array}{l}\text { 77. Desenvolver } \\
\text { espiritualidade }\end{array}$ & 0,531 & \\
\hline 78. Ter caridade & & 0,584 \\
\hline 79. Ser sóbrio & & 0,409 \\
\hline 82. Buscar diálogo & & 0,624 \\
\hline 83. Agir bom-senso & & 0,645 \\
\hline 84. Aconselhar-se & 0,719 & \\
\hline 85. Estar disposto & & 0,609 \\
\hline 87. Visitar imagens sagradas & 0,657 & \\
\hline 88. Amar a natureza & & 0,527 \\
\hline 89. Evitar comentários & & 0,478 \\
\hline 81. Confortar pessoas & & 0,606 \\
\hline 3. Rezar & 0,434 & \\
\hline 15. Procurar paz & & 0,431 \\
\hline 22. Ter consciência & & 0,421 \\
\hline
\end{tabular}

Tabela 3

Conjuntos formados pela prova post hoc de Tukey para externalização da religiosidade em relação aos grupos de idades

\begin{tabular}{lccc}
\hline \multirow{2}{*}{ Grupos de idade } & $n$ & \multicolumn{2}{c}{ alpha=0,05 } \\
\cline { 3 - 4 } & & 1 & 2 \\
\hline 1 & 144 & 88,11 & \\
2 & 204 & 89,05 & \\
3 & 117 & & 105,59 \\
$P$ & & 0,95 & 1 \\
\hline
\end{tabular}

Tabela 4

Conjuntos formados pela prova post hoc de Tukey para externalização da religiosidade em relação ao nível de religiosidade

\begin{tabular}{lccccc}
\hline \multirow{2}{*}{$\begin{array}{l}\text { Nível de } \\
\text { religiosidade }\end{array}$} & $n$ & \multicolumn{4}{c}{ alpha=0,05 } \\
\cline { 3 - 6 } & & 1 & 2 & 3 & 4 \\
\hline 1 & 11 & 46,54 & & & \\
2 & 65 & & 68,40 & & \\
3 & 163 & & & 93,27 & \\
4 & 127 & & & & 116,95 \\
$P$ & & 1 & 1 & 1 & 1 \\
\hline
\end{tabular}


Tabela 5

Conjuntos formados pela prova post hoc de Tukey para internalização da religiosidade em relação ao nível de religiosidade.

\begin{tabular}{lccc}
\hline \multirow{2}{*}{$\begin{array}{l}\text { Nível de } \\
\text { religiosidade }\end{array}$} & $n$ & \multicolumn{2}{c}{ alpha=0,05 } \\
\cline { 3 - 4 } & & 1 & 2 \\
\hline 1 & 11 & 148,09 & \\
3 & 162 & 153,85 & 153,85 \\
2 & 65 & 154,72 & 154,72 \\
4 & 127 & & 166,49 \\
$P$ & & 0,62 & 0,100 \\
\hline
\end{tabular}

Em acréscimo, pode-se pensar que os poucos recursos brasileiros para a medida da percepção de religiosidade também constituem uma razão importante para que novos instrumentos sejam pesquisados. E, nesse particular, são oportunas as asserções de Tinoco-Amador (2009), no sentido de que a medida do construto permite a compreensão e a elaboração de inferências que indivíduos e grupos têm sobre a experiência religiosa; assim como sobre as expressões sociais ou coletivas; as implicações pessoais e os estados evolutivos do desenvolvimento religioso; o significado da religião para a própria vida; ou as relações com saúde e

Tabela 6

Valores de alfa para os itens de externalização e internalização, caso eles fossem deletados.

\begin{tabular}{|c|c|c|c|}
\hline Itens do componente 1 & $\begin{array}{l}\text { Alfa se o item } \\
\text { for deletado }\end{array}$ & Itens do componente 2 & $\begin{array}{l}\text { Alfa se o item } \\
\text { for deletado }\end{array}$ \\
\hline 1. Ler a Bíblia & 0,951 & 9. Ser humilde & 0,937 \\
\hline 2. Ir à missa & 0,951 & 10. Amar o próximo & 0,937 \\
\hline 7. Participar eucaristia & 0,952 & 12. Respeitar ser humano & 0,937 \\
\hline 8. Confessar & 0,952 & 17. Ser prestativo & 0,936 \\
\hline 11. Ser missionário & 0,952 & 18. Ser solidário & 0,936 \\
\hline 13. Visitar doente & 0,953 & 25. Perdoar & 0,936 \\
\hline 14. Ter vida de oração & 0,952 & 26. Ser sereno & 0,936 \\
\hline 16. Viver a palavra & 0,952 & 28. Ser perseverante & 0,936 \\
\hline 20. Viver os sacramentos & 0,952 & 35. Fazer o bem & 0,935 \\
\hline 21. Educar na fé & 0,951 & 36. Ser acolhedor & 0,936 \\
\hline 23. Viver em comunhão & 0,952 & 37. Buscar a felicidade & 0,936 \\
\hline 29. Fazer jejum & 0,952 & 38. Ser justo & 0,936 \\
\hline 30. Buscar a santidade & 0,951 & 39. Ser sincero & 0,936 \\
\hline 31. Ouvir músicas & 0,952 & 40. Compreender & 0,936 \\
\hline 33. Fazer meditação & 0,954 & 41. Tratar semelhante & 0,936 \\
\hline 43. Fazer penitência & 0,953 & 42. Conviver em harmonia & 0,936 \\
\hline 45. Evangelizar & 0,950 & 48. Acolher com amor & 0,935 \\
\hline 46. Assistir a palestras & 0,951 & 50. Ser compreensivo & 0,936 \\
\hline 47. Ler livros & 0,951 & 52. Respeitar diferenças & 0,938 \\
\hline 57. Diálogo ecumênico & 0,953 & 53. Ser fraterno & 0,935 \\
\hline 63. Praticar os mandamentos & 0,952 & 54. Ser amável & 0,935 \\
\hline 65. Conhecer a religião & 0,952 & 55. Estar a serviço & 0,936 \\
\hline 66. Ouvir a palavra & 0,951 & 58. Autoaceitação & 0,947 \\
\hline 67. Entregar o dia & 0,951 & 59. Procurar ser melhor & 0,936 \\
\hline 68. Viver batismo & 0,951 & 60. Ser simples & 0,936 \\
\hline 69. Participar de movimentos & 0,951 & 61. Fazer com amor & 0,936 \\
\hline 70. Visitar os pobres & 0,953 & 62. Colocar-se no lugar & 0,937 \\
\hline 75. Rezar pelos inimigos & 0,953 & 64. Estender a mão & 0,936 \\
\hline 77. Desenvolver a espiritualidade & 0,952 & 71. Respeitar a família & 0,937 \\
\hline 84. Aconselhar-se & 0,951 & 73. Respeitar os idosos & 0,937 \\
\hline 87. Visitar SS & 0,952 & 74. Partilhar & 0,936 \\
\hline \multirow[t]{11}{*}{ 3. Analisar e controlar } & 0,956 & 76. Ter posição justa & 0,936 \\
\hline & & 78. Ter caridade & 0,935 \\
\hline & & 79. Ser sóbrio & 0,937 \\
\hline & & 82. Buscar diálogo & 0,936 \\
\hline & & 83. Agir com bom-senso & 0,936 \\
\hline & & 85. Estar disposto & 0,936 \\
\hline & & 88. Amar a natureza & 0,937 \\
\hline & & 89. Evitar comentários & 0,937 \\
\hline & & 81. Confortar pessoas & 0,936 \\
\hline & & 15. Procurar paz & 0,937 \\
\hline & & 22. Ter consciência & 0,937 \\
\hline
\end{tabular}

Nota: $\mathrm{SS}=$ Santíssima. 
bem-estar (Kim-Spoon et al., 2012; Miller \& Thoresen, 2003; Vaillant, 2013).

Assim, pretendeu-se neste estudo elaborar itens e realizar estudos psicométricos para a EAPRE. Partiu-se da compreensão de que a percepção de religiosidade é composta por uma dimensão interna e outra externa (Allport \& Ross, 1967; Lotufo Neto, 1997; Shannon, 2004). A primeira estaria mais voltada aos valores internos do indivíduo e ao modo como ele vive sua religiosidade, enquanto a segunda retrataria a demonstração do comportamento religioso e, em razão disso, seria externa.

A verificação da estrutura interna da EAPRE não resultou em ajuste adequado, o que indica que novas análises precisam ser realizadas com outras amostras e por métodos distintos (Horn, 1965; Hu \& Bentler, 1999; Lorenzo-Seva et al., 2011; O'connor, 2000). Adicionalmente, deve-se ter clareza de que o método utilizado, a análise dos componentes principais, por se basear na correlação linear das variáveis observadas, não caracteriza a variância comum distinta da específica, não se revelando o mais adequado, o que reitera a importância de que outros estudos sejam desenvolvidos (Damásio, 2012).

Quanto às diferenças de médias entre idades e sexos, foram encontrados resultados parcialmente favoráveis. Os participantes mais velhos se diferenciaram dos mais jovens apenas no fator Externalização, que está mais voltado à demonstração do comportamento religioso, como a ida ao templo religioso e a participação em grupos de discussão (Shannon, 2004). Algumas hipóteses podem ser aventadas: os mais velhos têm menor preocupação com a aceitação do comportamento religioso pelo grupo social, de modo que pode ser mais fácil assumir sua crença e seu comportamento religioso.
Ao lado disso, é possível pensar que os mais velhos também teriam mais tempo para se dedicar à religiosidade. Ocampo et al., (2006) encontraram menor frequência da internalização, em detrimento da externalização da religiosidade. Tais considerações podem compor a agenda de pesquisa para investigações futuras. Quanto ao sexo, não foram observadas diferenças significativas em relação aos dois fatores da EAPRE, o que não foi favorável aos estudos de Kahoe (1977) e Tinoco-Amador (2009). Em relação ao primeiro, o autor encontrou associação moderada negativa, apenas para as mulheres, entre religiosidade intrínseca e atitudes.

O estudo da comparação entre nível de religiosidade e pontuação na EAPRE, em ambos os fatores, revelou evidência de validade para a escala, pois ela se mostrou capaz de diferenciar os grupos de indivíduos com mais e menos percepção de religiosidade. Também nessa direção, os coeficientes de precisão da escala foram satisfatórios, visto que foram maiores que 0,90 para ambos os fatores. Dessa feita, é possível salientar que o objetivo do estudo foi atendido, embora, tal como afirmado anteriormente, outras pesquisas quanto aos parâmetros psicométricos devam ser realizadas.

A título de limitações do estudo, deve-se considerar que a amostra é de conveniência e inclui participantes de apenas um estado do país. Para além desse fato, uma agenda de pesquisa deve ser organizada, na qual poderão ser incluídos outros instrumentos, com o intuito de buscar outras evidências de validade baseadas na relação com outras variáveis. A relação de religiosidade com personalidade tem sido investigada, mais especialmente, com os fatores extroversão e neuroticismo do Big Five, assim como com as virtudes (Schuurmans-Stekhoven, 2013) e com o estresse (Powers, Cramer, \& Grubka, 2007).

\section{Referências}

Allport, G. W. \& Ross, J. M. (1967). Personal religious orientation and prejudice. Journal of Personality and Social Psychology, 5(4), $432-443$. Ávila, A. (2007). Para Conhecer a Psicologia da Religião. São Paulo: Edições Loyola.

Damásio, B. F. (2012). Uso da análise fatorial exploratória em psicologia. Avaliação Psicológica, 11(2), 213-228.

Dancey, C. P., \& Reidy, J. (2006). Estatística sem matemática para Psicologia. Porto Alegre: ArtMed.

Day, R. D., \& Acock, A. (2013). Marital Well-being and Religiousness as Mediated by Relational Virtue and Equality. Journal of Marriage and Family, 75(1), 164-177. doi: 10.1111/j.1741-3737.2012.01033.x

Emmons, R. A., \& Paloutzian, R. F. (2003). The psychology of religion. Annual Review of Psychology, 54, 377-402. doi: 10.1146/annurev. psych.54.101601.145024

Fleck, M. P. A. (2000). O instrumento de avaliação de qualidade de vida da Organização Mundial da Saúde (WHOQOL-100): características e perspectivas. Ciência E Saúde Coletiva, 5(1), 33-38. doi: 10.1590/S1413-81232000000100004

Glock, C. Y. (1962). On the study of religious commitment. Religious Education Research Supplement, 57, p. 98-110.

Gunnoe, M. J., \& Beversluis, C. D. (2009). And a Teen Shall Lead Them: The Relationship Between Worship Experiences and Youth Religiosity in the Panel Study of American Religiosity and Ethnicity (PS-ARE). Journal of Psychology and Christianity, 28(3), $236-247$.

Horn, J. L. (1965). A rationale and test for the number of factors in factor analysis. Psychometrika, 30(2), 179-185.

Hu, L. T., \& Bentler, P. M. (1999). Cutoff criteria for fit indexes in covariance structure analysis: conventional criteria versus new alternatives. Structural Equation Modeling, 6(1), 1-55. doi: 10.1080/10705519909540118

Kahoe, R. D. (1977). The psychology and theology of sexism. Journal of Psychology and Theology, 2, 284-290.

Kim-Spoon, J., Longo, G. S., \& McCullough, M. E. (2012). Parent-Adolescent Relationship Quality as a Moderator for the Influences of Parents' Religiousness on Adolescents' Religiousness and Adjustment.Journal of Youth and Adolescence, 41(12), 1576-1587. doi: 10.1007/s10964-012-9796-1 
Lo Bianco, A. C., \& Vidal, N. (2014). Novas expressões da religiosidade: o que elas dizem sobre o sujeito em sociedade hoje. Ágora, XVII(2), 177-186. Recuperado de http://www.redalyc.org/pdf/3765/376544072001.pdf

Lorenzo-Seva, U., Timmerman, M. E., \& Kiers, H. A. L. (2011). The Hull method for selecting the number of common factors. Multivariate Behavioral Research, 46(2), 340-364. doi: 10.1080/00273171.2011.564527

Lotufo Neto, F. (1997). Psiquiatria e Religião - a prevalência de transtornos mentais entre ministros religiosos. Tese de Livre Docência. Universidade de São Paulo, São Paulo.

Mattis, J. (2000). African American women's definitions of spirituality: A qualitative analysis. Journal of Black Psychology, 26(1), 101-122. doi: $10.1177 / 0095798400026001006$

Miller, W. R., \& Thoresen, C. E. (2003). Spirituality, religion, and health: An emerging research field. American Psychologist, 58(1), 24-35.

Ocampo, J. M., Romero, N., Saa, H. A., Herrera, J. A., \& Reyes-Ortiz, C. A. (2006). Prevalencia de lãs prácticas religiosas, fisfunción familiar, soporte social y sintomas depressivos em adultos mayores. Colombia Medica, 37(2), 26-30.

O'Connor, B. P (2000). SPSS and SAS programs for determining the number of components using parallel analysis and Velicer's MAP test. Behavior Research Methods, Instruments, \& Computers, 32(3), 396-402. Recuperado de http://web.ncyu.edu.tw/ fredli/sta/Mao-parallel.pdf

Oliveira, L. L. S., \& Balbinotto Neto, G. (2014). A Teoria do Mercado Religioso: evidências empíricas na literatura. REVER Revista de Estudos Religiosos, 14(1), 221-256. Recuperado de http://revistas.pucsp.br/index.php/rever/article/view/20282

Paiva, G. J., Garcia, A., Gonçalves, A. K., Scala, C. T., Faria, D. G. R., Gómez, M. L. T., Jordão, M. P., Barbosa, R. C., \& Franca, S. M. S. (2004). Experiência Religiosa e Experiência Estética em Artistas Plásticos: Perspectivas da Psicologia da Religião. Psicologia: Reflexão e Crítica, 17(2), 223-232.

Pargament, K. I. (2002). The Bitter and the Sweet: An Evaluation of the Costs and Benefits of Religiousness. Psychological Inquiry: An International Journal for the Advancement of Psychological Theory, 13(3), 168-181. doi: 10.1207/S15327965PLI1303 02

Peterson, C., \& Seligman, M. E. P. (2004). Character strengths and vitues: a handbook and classification. Washington, DC: American Psychological Association.

Powers, D. V., Cramer, R. J., \& Grubka, J. M. (2007). Spirituality, life stress and affective well-being. Journal of Psychology and Theology, 35(3), 235-243. Recuperado de http://www.thedivineconspiracy.org/Z5212E.pdf

Roehe, M. V. (2004). Experiência religiosa em grupos de auto-ajuda: o exemplo de neuróticos anônimos. Psicologia em Estudo, 9(3), $399-407$. doi: 10.1590/S0102-79722004000200010

Ruppel, H. (1969). Religiosity and Premarital Sexual Permissiveness: a methodological note. Sociology of Religion, 30(3), 176-188. doi: $10.2307 / 3710271$

Schultz, J. M., Tallman, B. A., \& Altmaier, E. M. (2010). Pathways to Posttraumatic Growth: The Contributions of Forgiveness and Importance of Religion and Spirituality. Psychology of Religion and Spirituality, 2(2), 104-114. doi: 10.1037/a0018454

Schuurmans-Stekhoven, J. B. (2013). Is God's call more than audible? A preliminary exploration using a two-dimensional model of theistic/ spiritual beliefs and experiences. Australian Journal of Psychology, 65(3), 146-155. doi: 10.1111/ajpy.12015

Shannon, C. M. (2004). An examination of the relationship between religiosity and the social self-efficacy of an individual. Recuperado de www.anselm.edu/internet/psych/theses.

Tinoco-Amador, J. R. (2009). Identificando los constructos de la religiosidad para jóvenes universitarios en México. Universitas Psychologica, 8(3), 807-829. Recuperado de http://www.redalyc.org/pdf/647/64712155019.pdf

Urbina, S. (2007). Fundamentos da Testagem Psicológica. Porto Alegre: Artes Médicas.

Vaillant, G. E. (2013). Psychiatry, religion, positive emotions and spirituality. Asian Journal of Psychiatry, 6(6), 590-594. doi: 10.1016/j. ajp.2013.08.073

Zinnbauer, B. J., Pargament, K. I., Cole, B., Rye, M. S., Butter, E. M., Belavich, T. G., Hipp, K. M., Scott, A. B., Kadar, J. L. (1997). Religiousness and spirituality: Unfuzzyimg the fuzzy. Journal for the Scientific Study of Religion, 36(4), 549-564. Recuperado de http:// www.psychology.hku.hk/ftbcstudies/refbase/docs/zinnbauer/1997/34_Zinnbauer_etal1997.pdf

\section{Sobre os autores}

Ana Paula Porto Noronha é psicóloga, Doutora em Psicologia Ciência e Profissão pela Pontifícia Universidade Católica de Campinas. Docente do Programa de Pós-Graduação Stricto Sensu em Psicologia da Universidade São Francisco. Bolsista Produtividade em Pesquisa do CNPq. Paulo André Céo Rosa é psicólogo pela Universidade São Francisco.

Luiz Felipe Ayres Bernardes é psicólogo e mestrando do Programa de Pós-Graduação Stricto Sensu em Psicologia da Universidade São Francisco. 